\title{
PENGEMBANGAN MEDIA PRESENTASI INTERAKTIF SEMI LABORATORIUM VIRTUAL PADA POKOK BAHASAN LISTRIK DINAMIS
}

\author{
Jushadi Arman Saz ${ }^{1)}$, Fadhila $^{2)}$, Nurhayati ${ }^{3)}$, Ahmad Yani ${ }^{4)}$ \\ ${ }^{1,3,4)}$ Jurusan Fisika FMIPA Universitas Negeri Makassar \\ ${ }^{2)}$ Jurusan Pendidikan Fisika FMIPA Universitas Sulawesi Barat \\ Email: czar.hadi@gmail.com, fadhilaphysics@gmail.com
}

\begin{abstract}
Abstrak
Penelitian ini adalah penelitian pengembangan yang secara umum bertujuan untuk: (1) Mengembangkan bahan ajar Fisika/bahan bacaan siswa pada pokok bahasan listrik dinamis untuk SMA kelas X semester 2 dan (2) Mengembangkan produk perangkat pembelajaran Fisika berbasis komputer berupa media presentasi interaktif semi laboratorium virtual untuk pembelajaran di kelas. Model pengembangan media yang digunakan adalah model R2D2, terdiri dari tiga tahap yaitu: (1) penetapan (define), (2) perancangan (design), pengembangan (develop) dan (3) diseminasi terbatas (disseminate). Penelitian ini dilaksanakan dijurusan Fisika, FMIPA Universitas Negeri Makassar mahasiswa S1. Analisis data yang digunakan dalam penelitian ini adalah analisis statistik deskriptif. Statistik deskriptif digunakan untuk menganalisis kesahihan media presentasi interaktif Semi Laboratorium Virtual pada pokok bahasan listrik dinamis. Media presentasi interaktif divalidasi oleh seorang pakar media pembelajaran dan dilakukan penilaian oleh praktisi yakni mahasiswa program pascasarjana (S2) yang berprofesi sebagai guru sebanyak 13 orang dan uji coba terbatas dilakukan pada mahasiswa jurusan fisika (S1) sebanyak 6 orang. Hasil penelitian menunjukkan bahwa media presentasi interaktif Semi Laboratorium Virtual meliputi penilaian validator (ahli dan praktisi) memberikan penilaian rata-rata 89,2\% untuk kulitas perangkat lunak dan 87,5\% untuk daya tarik, dan penilaian Untuk hasil penilaian oleh praktisi diperoleh rata-rata persentase untuk kepraktisan dan sistematika media presentasi interaktif adalah $88 \%$ atau tergolong dalam kategori baik. Pada saat uji coba terbatas juga secara rata-rata diperoleh penilaian $82 \%$ semua berada pada kategori baik. Hasil penilaian tersebut lebih tinggi dari standar penerimaan yang telah ditentukan yaitu 75,0 $\%$, hal ini menunjukkan bahwa perangkat lunak presentasi yang merupakan media pembelajaran yang diperuntukkan untuk Guru sebagai media presentasi interaktif Semi Laboratorium Virtual dalam melakukan pembelajaran di kelas, memenuhi kesahihan atau valid untuk digunakan sebagai media dalam pelaksanaan pembelajaran.
\end{abstract}

Kata kunci: media presentasi, interaktif, listrik dinamis, semi virtual laboratory.

\section{PENDAHULUAN}

Pemahaman siswa tentang bagaimana arus listrik mengalir dalam kawat masih bersifat abstrak, sebab didasarkan pada fenomena gerakan elektron. Perpaduan antara kajian materi dan eksperimen di laboratorium merupakan cara belajar yang dapat menguatkan pemahaman tentang materi-materi IPA secara umum dan materi fisika secara khusus. Sebelum melakukan praktik dilaboratorium, siswa perlu memiliki pengetahuan awal tentang apa yang akan dipraktikkan, baik pengetahuan tentang konsepkonsep, prinsip-prinsip, dan hukum-hukum yang terkait dengan apa yang akan dipraktikkan, dan tidak kalah pentingnya adalah bagaimana melakukan praktikum itu sendiri. Pemberian tutorial berupa eksperimen dalam laboratorium virtual melalui perangkat lunak komputer maupun visualisasi tentang eksperimen dapat membantu siswa mempersiapkan diri memasuki ruang laboratorium untuk melakukan eksperimen dengan peralatan yang sesungguhnya, menghindari kerusakan yang tidak perlu, atau meminimalisir bahaya yang dapat diakibatkan dari kelalaian penggunaan alat praktik.

Salah satu sarana yang dapat diandalkan dalam dunia pendidikan adalah komputer, kemajuan teknologi informasi banyak didukung oleh kemajuan perangkat keras maupun perangkat lunak komputer. Tenaga pendidik tentunya tidak boleh tertinggal dalam memanfaatkan teknologi termasa termasuk komputer. Pembelajaran berbasis komputer bukanlah sesuatu yang baru, dan langka, hampir di semua jenjang pendidikan telah mengenal sistem pembelajaran tersebut dalam wujud dan variasi yang berbeda mulai dari sistem stand alone, berbasis jaringan terbatas, sampai yang berbasis internet. 
Sebuah survei yang diselenggarakan Asosiasi Penyelenggara Jasa Internet Indonesia (APJII) mengungkapkan bahwa jumlah pengguna internet di Indonesia tahun 2012 mencapai 63 juta orang atau 24,23 persen dari total populasi negara ini.Tahun 2013, angka itu diprediksi naik sekitar 30 persen menjadi 82 juta pengguna dan terus tumbuh menjadi 107 juta pada 2014 dan 139 juta atau 50 persen total populasi pada 2015. (Yusuf, 2013).

Produk yang dalam penelitian ini dihasilkan dapat disimpan dalam bentuk keping CD, Flash Disk, maupun diakses melalui internet dan internet. Berdasarkan latar belakang di atas, penulis merasa perlu untuk mengembangkan media presentasi interaktif Semi Laboratorium Virtual pokok bahasan listrik dinamis.

Rumusan masalah dalam penelitian ini adalah bagaimana profil produk media presentasi interaktif Semi Laboratorium Virtual pada pokok bahasan listrik dinamis untuk SMA kelas X semester 2 ?

Tujuan penelitian ini sebagai berikut:

1. Mengembangkan bahan ajar Fisika / bahan bacaan siswa pada pokok bahasan listrik dinamis untuk SMA kelas X semester 2.

2. Mengembangkan produk perangkat pembelajaran Fisika berbasis komputer berupa media presentasi interaktif semi laboratorium virtual pada pokok bahasan listrik dinamis untuk pembelajaran di kelas.

Dengan spesifikasi produk yang diharapkan sebagai berikut:

a. Bahan ajar / bahan bacaan siswa

b. Media presentasi interaktif

\section{METODE PENELITIAN}

Mengacu pada rumusan masalah yang telah dikemukakan maka penelitian ini bersifat research and development $(R \& D)$. Model pengembangan pada peneltian ini difokuskan pada produk yang akan dihasilkan yaitu buku ajar pokok bahasan listrik dinamis dan media presentasi interaktif semi laboratorium virtual pada pokok bahasan listrik dinamis. Untuk mencapai tujuan ini dipergunakan model R2D2 (Recursive, Reflective Design and Development model) Willis, J. (1995).

Model R2D2 memiliki tiga komponen yaitu: (1) pendefinisian (define), (2) desain dan pengembangan (design and development), dan (3) penyebarluasan (disseminate). Sepintas model ini memiliki komponen yang sama dengan model 4D dari Thiagaraian, Semmel, dan Semmel (1974). Namun, dalam model 4D komponen umumnya dianggap bersifat sekuensial atau linier. Sebagian besar model desain instruksional tradisional didasarkan pada seperangkat tahapan berurutan atau fase, yang dapat dengan mudah diwakili oleh diagram alur.

Berbeda dengan model R2D2, alur pengembangan tidak dapat digambarkan secara linier. Pada model R2D2 keempat komponen tersebut diletakkan pada tiga titik fokus. Desainer tidak harus bekerja secara berurutan, misalnya, pertama-tama harus fokus pada komponen pendefinisian. Model ini juga rekursif atau iteratif serta reflektif dan partisipatif. Aspek desain dan komponen pengembangan, misalnya, dapat menjadi fokus perhatian beberapa kali selama proses desain instruksional. Hal ini diharapkan agar penyusun desain instruksional untuk aktif merefleksikan dan menganalisa kerja dan teratur merevisi kedua aspek yang sedang dikembangkan dan model yang mendasari perkembangannya.

Model desain pengembangan R2D2 dapat digambarkan sebagai berikut:

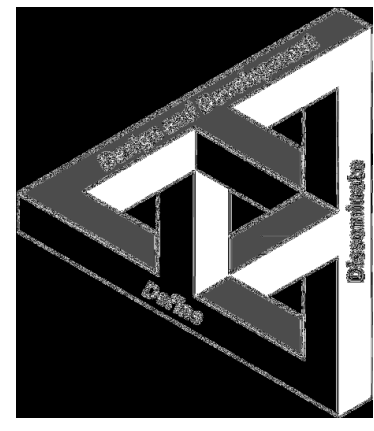

Gambar 2.1. Ilustrasi Model R2D2 
Model ini memiliki tiga titik fokus (pendefinisian, desain dan pengembangan, dan penyebarluasan). Sifat grafik yang tidak memiliki awal atau akhir yang jelas dan membangun sebuah perspektif "dunia tidak mungkin", mewakili dua huruf R dari model R2D2: Rekursif dan Refleksi.

Gambar tersebut merupakan adaptasi dari Escher's impossible tribar (Ernst, 1994). Sebuah impossible tribar adalah segitiga yang memiliki tiga sudut 90 derajat. Tiga segitiga mustahil membentuk satu segitiga mustahil yang lebih besar dengan setiap sisi merupakan salah satu titik fokus model: pendefinisian, desain dan pengembangan, serta penyebarluasan.

Pada model R2D2, proses tidak beralih dari satu tahap ke tahap berikutnya jika satu tahap telah selesai secara linier. R2D2 bersifat rekursif dan reflektif, artinya satu masalah dapat ditinjau ulang beberapa kali selama proses berlangsung sehingga solusi, keputusan dan alternatif muncul secara bertahap selama proyek.

Subjek dalam penelitian ini adalah media presentasi interaktif semi laboratorium virtual yang dikembangkan dan dilengkapi buku bacaan siswa pada pokok bahasan listrik dinamis untuk SMA kelas X. Prosedur pengembangan berdasarkan model R2D2 yang teridiri atas tiga komponen yang disesuaikan pada langkah prosedur pengembangan media presentasi interaktif akan dibuat dengan langkah-langkah sebagai berikut :

1. Pendefinisian (define) meliputi :

a. Menetapkan materi pembelajaran

b. Menganalisis kebutuhan

2. Desain dan pengembangan (design and develop) meliputi:

a. Mengembangkan Materi Pembelajaran

b. Menyusun skenario alur tayangan dan pemrograman

c. Menyusun daftar penyesuaian piranti lunak dan pemanfaatannya

d. Produksi

3. penyebarluasan (desseminate) meliputi :

a. Validasi dan uji coba

b. Revisi dan penyempurnaan

\subsection{Penetapan Fokus Pendefinisian}

Pendefinisian berfokus pada pembentukan tim kolaboratif, dan perumusan masalah. Tim kolaboratif yang akan dilibatkan meliputi ahli media, ahli materi, ahli pembelajaran dan audiens terbatas. Para ahli akan memvalidasi bidang sesuai keahliannya masing-masing. Untuk uji isi yang berkaitan dengan materi fisika pokok bahasan listrik dinamis SMA kelas X semester II, akan berkolaborasi peneliti, dengan mahasiswa S2 program studi fisika pada Program Pascasarjana UNM sebagai praktisi. Ahli media dan peneliti akan berkolaborasi dalam menyusun skenario pembuatan perangkat lunak paket multimedia pembelajaran, dan para mahasiswa S1 fisika sebagai audiens terbatas akan berkolaborasi dalam uji coba penerapan media presentasi interaktif Semi Laboratorium Virtual.

\subsection{Fokus Desain Pengembangan}

Desain dan pengembangan berfokus pada pembuatan media presentasi interaktif Semi Laboratorium Virtual melalui uji ahli, praktisi, dan uji coba terbatas pada mahasiswa S1 Jurusan Fisika FMIPA UNM. Pengembangan media mencakup (1) Pembuatan buku ajar. (2) media presentasi interaktif.

\subsection{Fokus Penyebarluasan.}

Mengingat batas akhir waktu penyelesaian, maka tahap diseminasi pada penelitian ini tidak dilaksanakan secara luas.

\subsection{Uji Coba Produk}

Uji coba media presentasi interaktif Semi Laboratorium Virtual bertujuan untuk menghasilkan produk yang layak. Didalam ujicoba akan dipelajari kelemahan-kelemahan untuk direvisi. Berikut akan dikemukakan desain uji coba, subyek uji coba, jenis data, teknik pengumpulan data dan instrumen, dan teknik analisis data. 


\subsection{Desain Uji Coba}

Produk berupa media presentasi interaktif Semi Laboratorium Virtual melalui uji coba ahli pembelajaran, uji coba ahli materi, uji coba praktisi (Mahasiswa S2 Program Studi Fisika PPs UNM) dan mahasiswa kelompok kecil pada mahasiswa S1 jurusan Fisika FMIPA UNM.

\subsection{Jenis Data}

Data yang akan dijaring, berdasarkan saat perolehan dibagi atas dua:

Data yang akan dijaring saat pengembangan meliputi data verbal tulis dan data verbal lisan. Data verbal lisan diperoleh dari para ahli dan praktisi berupa saran, sanggahan, arahan dan interprestasi tentang pengembangan produk media presentasi interaktif Semi Laboratorium Virtual yang dikembangkan dalam penelitian ini. Data yang akan dijaring berupa data kualitatif dan kuantitatif. Data kualitatif berupa saran, kritikan dan komentar dari praktisi (Mahasiswa S2 Program Studi Fisika PPs UNM). Data dari Mahasiswa berupa penilaian pada ujicoba terbatas dan pada saat implementasi terbatas, data tersebut adalah:

Penilaian mahasiswa terhadap kelayakan media presentasi interaktif Semi Laboratorium Virtual. Instrumen yang digunakan untuk menjaring data dalam penelitian ini meliputi instrumen untuk menjaring data dari ahli, pakar, praktisi dan Mahasiswa, berupa koesioner tentang daya tarik penggunaan media presentasi interaktif Semi Laboratorium Virtual.

Metode angket digunakan untuk mengukur indikator pengembangan yang berkenaan dengan kualitas isi perangkat lunak media presentasi interaktif yang telah dibuat yang meliputi materi, tampilan, kemudahan penggunaan, dan kualitas teknik pembuatan. Angket menggunakan format respon empat poin dari skala likert, dimana alternatif responnya adalah Sangat setuju (SS), Setuju (S), Kurang Setuju (KS) dan tidak setuju (TS).

Penentuan skor skala Likert dilakukan secara apriori. Skala yang diberikan yaitu,skor 4 untuk sangat setuju (SS), skor 3 untuk setuju (S), skor 2 untuk kurang setuju (KS), dan skor 1 untuk tidak setuju (TS). Sedangkan bagi skala yang berarah negatif maka skor menjadi sebaliknya. Validitas yang digunakan dalam penelitian ini adalah validitas logis (logical validity). Untuk membuat validitas logis dalam penelitian ini, maka pembuatan instrumen mengikuti langkah-langkah hati-hati, yaitu dengan memecah variabel menjadi beberapa indikator, kemudian merumuskan butir-butir pernyataan. Dengan demikian, secara logis akan dicapai validitas instrumen seperti yang dikehendaki dalam penelitian ini.

Angket yang digunakan untuk mengumpulkan data dalam penelitian ini meliputi angket Black Box Test dan Alpha Test. Black Box Test digunakan untuk menguji fungsi perangkat lunak yang telah dibuat tentang cara pengoperasian dan kegunaannya, apakah data, pengkodean serta hyperlink antar file sudah sesuai dengan yang diharapkan. Pada penelitian ini ditetapkan bahwa suatu kriteria atau bagian dalam media presentasi interaktif ini akan diperbaiki bila dari 75\% jawaban responden angket Black Box Test merupakan jawaban negatif. Apabila lebih dari $75 \%$ jawaban dari responden angket Black Box Test merupakan jawaban positif maka kegiatan penelitian dilanjutkan dan analisa hasil penelitian menggunakan angket Alpha Test.

Setelah data diperoleh, selanjutnya adalah menganalisis data tesebut. Penelitian ini lebih menitikberatkan pada bagaimana mengembangkan media presentasi interaktif Semi Laboratorium Virtual, sehingga data dianalisis dengan sistem deskriptif. Untuk menganalisis data hasil angket dilakukan langkah-langkah sebagai berikut:

1. Mengkuantitatifkan hasil angket sesuai dengan indikator yang telah ditetapkan dengan memberikan skor sesuai dengan bobot yang telah ditentukan sebelumnya.

2. Membuat tabulasi data.

3. Menghitung persentase dari tiap-tiap subvariabel dengan rumus:

$$
\mathrm{P}(\mathrm{s})=(\mathrm{S} / \mathrm{N}) * 100
$$

$P(s)=$ persentase sub variabel

$S=$ jumlah skor tiap sub variabel

$N=$ jumlah skor maksimum

(Ali dalam Kristiningrum, 2007:41)

4. Dari persentase yang telah diperoleh kemudian ditransformasikan kedalam tabel supaya pembacaan hasil penelitian menjadi mudah. 
Untuk menentukan kriteria kualitatif dilakukan dengan cara:

a. Menentukan persentase skor ideal (skor maksimum) $=100 \%$.

b. Menentukan persentase skor terendah (skor minimum) $=0 \%$.

c. Menentukan range $=100-0=100$.

d. Menentukan interval yang dikehendaki $=4$ (baik, cukup, kurang, dan tidak baik).

e. Menentukan lebar interval $(100 / 4=25)$.

Selanjutnya, secara kontinum digambarkan tingkat gradasi hasil analisis, maka range persentase dan kriteria kualitatif dapat ditetapkan sebagai berikut:

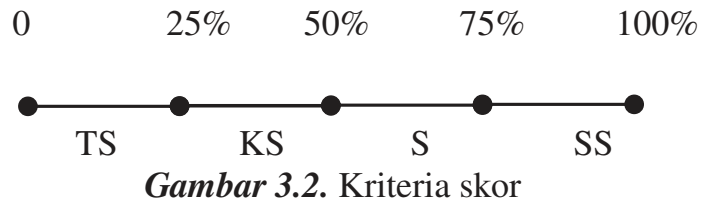

\begin{tabular}{|c|c|c|c|}
\hline$\%$ & $\leq$ & skor $\leq 100 \%$ & $=$ Baik \\
\hline 0 & 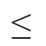 & skor $\leq 75 \%$ & $=$ Cukup baik \\
\hline & & skor $\leq 50 \%$ & $=$ Kurang baik \\
\hline & & skor $\leq 25 \%$ & $=$ Tidak baik \\
\hline
\end{tabular}

Penelitian ini dikatakan berhasil apabila dari angket diperoleh hasil yang berada pada rentang $76 \% \leq$ skor $\leq 100 \%$ dan $51 \% \leq$ skor $\leq 75 \%$ atau pada kriteria "Baik" dan "Cukup Baik.

\subsection{Tahap Pendefenisian (define)}

\section{HASIL DAN PEMBAHASAN}

Sebelum pembuatan media presentasi interaktif Semi Laboratorium Virtual ada beberapa hal yang perlu di analisis sebagai berikut :

a. Pokok bahasan listrik dinamis untuk SMA kelas X semester 2 Kompetensi Dasar Menerapkan konsep kelistrikan dalam berbagai penyelesaian masalah dan berbagai produk teknologi. (materiyang diambil meliputi : Arus listrik dan beda potensial, kuat arus listrik, hukum ohm, hukum I kirchoff, rangkaian resistor, dan hukum II Kirchoff). Analisis terhadap materi pelajaran dilakukan melalui kegiatan studipustaka terhadap buku-buku atau literatur yang terkait tentang pokokbahasan listrik dinamis untuk siswa SMA kelasX.

b. Analisis penggambaran materi yang dapat terkomputerisasi. Hal ini dilakukan untuk memilih gambar, video, atau animasi yang mudah menggambarkan materi yang akan dibahas dalam media presentasi interaktif. Dilakukan secara selektif dan melalui proses revisi untuk meminimalisir kemungkinan timbulnya miskonsepsi akibat visualisasi yang kurang tepat.

c. Menentukan perangkat lunak utama dan perangkat lunak pendukung yang akan digunakan dalam penyusunan media presentasi interaktif.

\subsection{Tahap Desain dan pengembangan (design and develop)}

Pada tahap ini dilakukan kegiatan - kegiatan sebagai berikut :

\subsubsection{Menyusun Bahan Bacaan}

Bahan bacaan yang disusun dijadikan bahan dalam penyusunan perangkat lunaktutorial pembelajaran, yang dapat dipelajari secara mandiri oleh siswa.

3.2.2 Menyusun Perangkat lunak pembelajaran (produksi)

Perangkat lunak pembelajaran yang disusun terdiri atas, (1) buku ajar sebagai bahan bacaan pendamping bagi siswa, (2) perangkat lunak untuk pembelajaran di kelas, yaitu media presentasi interaktif Semi Laboratorium Virtual yang akan digunakan guru dalam pelaksanaan pembelajaran. Perangkat lunak presentasi bertujuan untuk memudahkan Guru dalam melakukan pembelajaran di kelas, perangkat lunak tersebut bersifat interaktif, sehingga memungkinkan guru atau tenaga pengajar untuk menyajikan materi secara interaktif walaupun dalam bentuk presentasi.

\subsubsection{Validasi}

Validasi ahli yang dilibatkan meliputi ahli dibidang materi atau konten dan ahli media pembelajaran. Ahli media terdiri atas satu orang doktor pengajar media pembelajaran fisika. 
Tabel 3.1. Hasil Validasi Ahli Tentang Kualitas TampilanPerangkat Lunak Presentasi

\begin{tabular}{clcc}
\hline No. & Aspek yang dinilai & Skor & Keterangan \\
\hline 1. & Kombinasi latar depan dan latar belakang sesuai & 90 & Baik \\
\hline 2. & Teks atau tulisan mudah terbaca & 90 & Baik \\
\hline 3. & Animasi tampilan menarik & 95 & Baik \\
\hline 4. & Gambar mendukung peyampaian materi & 90 & Baik \\
\hline 5. & $\begin{array}{l}\text { Tata letak gambar, grafik dan teks memudahkan } \\
\text { penyimak untuk memahami materi }\end{array}$ & 95 & Baik \\
\hline 6. & Iringan musik mendukung suasana belajar & 90 & Baik \\
\hline & Rata - rata & 92 & Baik \\
\hline
\end{tabular}

Tabel 3.2. Hasil Validasi Ahli Tentang Daya TarikPerangkat Lunak Presentasi

\begin{tabular}{clcc}
\hline No. & Aspek yang dinilai & Skor & Keterangan \\
\hline 1. & Warna layar depan (gambar dan huruf) menarik & 95 & Baik \\
\hline 2. & Huruf dan kalimat judul menarik perhatian & 95 & Baik \\
\hline 3. & Gambar, ilustrasi, grafik dan video menarik perhatian & 95 & Baik \\
\hline 4. & Tata letak menarik perhatian & 95 & Baik \\
\hline 5. & Animasi penggalan tampilan menarik perhatian & 95 & Baik \\
\hline 6. & Tata suara menarik perhatian & 95 & Baik \\
\hline \multicolumn{2}{c}{ ata - rata } & $\mathbf{9 5}$ & Baik \\
\hline
\end{tabular}

Tabel 3.3. Hasil Penilaian Media PresentasiInteraktif

\begin{tabular}{clcc}
\hline No & \multicolumn{1}{c}{ Aspek yang dinilai } & Skor $\mathbf{\%})$ & Ket \\
\hline 1. & Kombinasi latar depan dan latar belakang sesuai & 85 & Baik \\
\hline 2. & Teks atau tulisan mudah terbaca & 88 & Baik \\
\hline 3. & Animasi tampilan menarik & 92 & Baik \\
\hline 4. & Gambar mendukung penyampaian materi & 88 & Baik \\
\hline 5. & Tata letak gambar, grafik dan teks memudahkan \\
& penyimak untuk memahami materi & 90 & Baik \\
\hline 6. & Warna layar depan (gambar dan huruf) menarik & 87 & Baik \\
\hline 7. & Gambar, ilustrasi, grafik dan video menarik perhatian & 87 & Baik \\
\hline 8. & Tata letak menarik perhatian & 85 & Baik \\
\hline 9. & Penggunaan tombol navigasi konsisten & 87 & Baik \\
\hline 10. & Tombol navigasi mudah dipahami & 85 & Baik \\
\hline 11. & Menggunakan kalimat yang sederhana dan padat & 96 & Baik \\
\hline 12. & Materi tidak menganderung miskonsepsi & 87 & Baik \\
\hline 13. & Penyajian materi sistematis & 88 & Baik \\
\hline 14. & Gambar, ilustrasi, grafik dan video menuntun untuk & 88 & Baik \\
\hline & memahami materi & $\mathbf{8 8}$ & Baik \\
\hline
\end{tabular}

Hasil penilaian media presentasi oleh praktisi menghasilkan persentase $88 \%$ atau tergolong kategori baik, sehingga media presentasi interaktif yang telah dibuat memenuhi kriteria praktis dan sistematis.

\section{KESIMPULAN}

Berdasarkan hasil penelitian yang telah dilakukan dapat disimpulkan sebagai berikut:

1. Telah disusun buku ajar dan media presentasi interaktif Semi Laboratorium Virtual pada pokok bahasan Listrik Dinamis untuk SMA kelas X semester 2.

2. Hasil validasi dari ahli, dan praktisi, serta penilaian mahasiswa pada saat ujicoba terbatas, secara keseluruhan memberikan penilaian dalam kategori baik, dengan rincian yaitu validasi oleh ahli 
media diperoleh persentase untuk kualitas tampilan adalah sebesar 92\% dan untuk daya tarik diperoleh 95\%, hasil penilaian olehpraktisi diperoleh hasil untuk sisi kepraktisan dan sistematika diperoleh hasil persentase $88 \%$ sedangkan hasil ujicoba terbatas diperoleh hasil persentase sebesar $82 \%$ dengan demikian media presentasi interaktif Semi Laboratorium Virtual yang telah dikembangkan layak digunakan dalam pelaksanaan proses pembelajaran fisika khususnya pokok bahasan Listrik Dinamis.

\section{SARAN}

Berdasarkan pengalaman selama pelaksanaan penelitian dan hasil penelitian disarankan :

1. Kepada guru pengguna perangkat lunak yang telah dikembangkan ini, yaitu media presentasi interaktif Semi Laboratorium Virtual, diharapkan berlatih terlebih dahulu agar menguasai perpindahan tiap scene slide.

2. Mempersiapkan dan menguji segala sarana dan alat bantu berupa hardware yang akan digunakan sebelum melakukan presentasi

3. Menggunakan alat bantu yang memudahkan untuk mengatur navigasi antar slide misalnya dengan menggunakan wireless presenter ataus martboard sehingga siswa dan guru dapat mengoptimalkan fungsi media presentasi interaktif Semi Laboratorium Virtual yang telah dibuat.

4. Aplikasi presentasi interaktif ini masih terdapat kekurangan dalam tampilan animasi, sehingga diharapkan untuk pengembangan selanjutnya dapat dibuat aplikasi animasi yang dianalisis lebih mendalam sehingga dapat membangun konsep pada diri siswa serta membantu meminimalisir timbulnya miskonsepsi terutama pada mata pelajaran fisika.

5. Agar dibuatkan media presentasi interaktif untuk pokok bahasan lain yang lebih bersifat abstrak sehingga dapat membantu dalam proses pengajaran fisika.

\section{DAFTAR PUSTAKA}

Amin, M. 1984. Hakekat sains. Yogyakarta : FPMIPA IKIP Yogyakarta.

Beiser, Arthur.1992. Konsep Fisika Modern (Edisi Keempat). Jakarta: Gelora Akasara Pratama.

Berg, B. L. (2007). Qualitative Research Methods for the Social Sciences. Boston: Pearson Education, Inc.

Criswell L. Eleanor, (1989), The Design of Computer Based Instruction, New York:

Macmilan Publishing Company.

Edwards, Clifford H. \& Fisher, Robert F. 1977. Teaching Elementary School Science :A CompetencyBased Approach. New York: Praeger Publisher.

Harun, Jamaluddin. Tasir Zaidatun. 2003. Multimedia dalam Pendidikan. Bontang: PTS Publication

Hasrul, 2010. Jurnal MEDTEK, Volume 2, Nomor 1, Halaman 2.

Hocine Belmili, 2011, Semi-Virtual Laboratory Design For Photovoltaic Generator characterization

Performance, http://www.ep.liu.se/ecp/057/vol11/032/ecp57vol11_032.pdf, diakses tanggal 1 Mei 2013.

Kristiningrum. 2007. Pengembangan Multimedia Pembelajaran Interaktif dengan Macromedia Authorware 7.0 Pada Materi Fisika Sekolah Menengah Atas (SMA) Pokok Bahasan Kinematika Gerak Lurus. Skripsi.Semarang: Unnes.

Kuslan, L. \& A.H. Stone. 1969. Teaching children science: an inqury approachs. California: Wadsworth Publishing Company, Inc.

Rusman, 2011. Pembelajaran Berbasis Teknologi Informasi dan Komunikasi Mengembangkan Profesionalisme Guru. Jakarta: RajaGrafindo Persada.

Sumaji., Soehakso., Wijaya,M. dkk. 1998. Pendidikan Sains yang Humanistis. Yogyakarta: Kanisus.

Hubbard, Peter et al. 1983. A training Course for TEFL, Oxford University Press:

Oxford.

Jerry Willis, 2000, A General Set of Procedures for Constructivist Instructional Design: The New R2D2 Model, http://www.lavaredwards.com/edpsych/research/R2D2.pdf, diakses tanggal 1 Mei 2013.

Jerry Willis, 2000, Constructivist Instructional Design: Creating a Multimedia Package for Teaching Critical Qualitative Research, http://www.nova.edu/ssss/QR/QR5-1/colon.html, diakses tanggal 1 Mei 2013. 
Marc Couture, 2003, The Virtual Physics Lab (VPLab), http://benhur.teluq.uqam.ca/ mcouture/lvp/vplab/VPLdesc.htm, diakses tanggal 1 Mei 2013.

Teunis (Tim) Roos, 2012, The R2D2 Model of Instructional Design, http:/etec.ctlt.ubc.ca/510wiki/The_R2D2_Model_of_Instructional_Design diakses tanggal, 1 Mei 2013.

Yusuf, Oik, 2012, 2013, Pengguna Internet Indonesia Bisa Tembus 82 Juta, http://tekno.kompas.com/read/2012/12/13/10103065/2013.pengguna.internet.indonesia.bisa.te mbus.82.juta, diakses tanggal 1 Mei 2013.

Zen, M.T. 1984. Sains, Teknologi dan Hari Depan Manusia. Jakarta : Gramedia 